\title{
Edyta Szymkowiak
}

(Uniwersytet im. A. Mickiewicza w Poznaniu, Poznań - Polska)

\section{ПОПЫТКА „КРУГООБРАЗНОГО” ПРОЧТЕНИЯ РОМАНА ИАИОТ Ф.М. АОСТОЕВСКОГО (АНААИЗ ПОСАЕАНЕЙ СЦЕНЫ)}

Фабульное пространство романа Идиот растягивается в диапазоне обведенным будто двумя весьма значительными эпизодами, выделяющимися на фоне целой сюжетной линии произведения присутствием Мышкина и Рогожина ${ }^{1}$. Инициальная конфронтация пары главных героев имеет место в поезде Петербургско-Варшавской железной дороги подходящем к Петербургу, в свою очередь, горизонт их последней встречи намечает сцена у тела Настасьи Филипповны в квартире Рогожина. Если первое столкновение наименовать „завязкой” контакта между двумя героями, тогда совместный досмотр за телом Настасьи Филипповны, предстает в виде „развязки" как их взаимного общения, так и сюжетной интриги произведения в целом. Интересно обратиться к будто валоризированному диагнозу финальной сцены, поставленному самым Достоевским.

Наконец, и главное для меня в том, что эта 4-я часть и окончание ее - самое главное в моем романе, то есть для развязки романа почти и писался и задуман был весь роман ${ }^{2}$.

Если буквально отнестись к словам автора Преступления и наказания, тогда финальную сцену, композиционно завершающую сюжетное пространство романа Идиот, можно рассматривать в качестве первоначальной сцены инициирующей, а может даже, детерминирующей ход мнимо предшествующих ей действий.

Такая установка, предоставляющая возможность подойти к исследуемой теме обратным или вернее круговым путем, значительно изменяет перспективу интерпретационного осмотра художественного текста. Запускаемый нами процесс сферического чтения, размещенный, казалось бы, в решающей (обреченной на непредотвра-

1 Здесь финальной сценой мы считаем именно „последнюю” встречу Мышкина и Рогожина у тела Настасьи Филипповны. Не принимается во внимание XII глава - Заключение. См.: Г. Ермилова, Трагедия „русского Христа" или о неожиданности окончания "Идиота", http:// komdost.narod.ru/ermil.htm (01.11.2012).

2 Ф.М. Достоевский, Письма, http://www.croquis.ru/2558.html (01.11.2012). 
тимость) сцене, упраздняет будто внешнюю границу перцепции текста, вводя объектного по отношению к нему читателя в имманентную ось своей движущейся реальности. ${ }^{3}$ Тем самым, художественное пространство органично ассимилирует познавательный элемент посвящаемого читателя4, впрягая его в кругообразный процесс стимуляции текста.

Примечательно, что на уровне сюжетного пространства аналогичный, хотелось бы сказать, ритуал инициации выпадает на долю главного героя, именно в „последнем" эпизоде романа. Движимый внутренним приказом познания князь Мышкин отправляется из лебедевской дачи в Павловске в Петербург. Сразу после приезда спешит в рогожинский дом, однако там не находит подразумеваемой, интуитивной цели своего будто не вполне осознанного визита. „Двери затворились" 5 . Неудовлетворенный полученным от старой служанки ответом заходит во двор, где встречает дворника. Тот также не в состоянии передать ему желательную информацию. Затем Мышкин направляется в Измайловский полк, где находилась нанимаемая от вдовы-учительши квартира Настасьи Филипповны. Оттуда также уходит ни с чем. Вторично пытается навести справку в рогожинском доме, но „не отворяется даже и дверь в квартиру старушки" (с. 623). Безуспешным является также повторный и лаконичный разговор с дворником, подозрительно нежелающим передать никакого сведения на тему Рогожина. Затем князь решает навестить знакомую немку Настасьи Филипповны, проживающую в Семеновском полке. И тот визит оказывается напрасным. Недовольный таким положением вещей Мышкин стремится на Литейную, где снимает номер в гостинице. После некоторого времени снова бросается к Рогожину. Ситуация повторяется: Рогожина не было, „на звон не отпирали" (с. 624). Князь опять отправляется в Измайловский полк к учительше...

Наблюдаем, что главный герой безрезультатно хочет добиться предоставления какой-нибудь информации на тему пребывания то ли Рогожина, то ли Настасьи Филипповны в Петербурге, каждый раз получая негативный ответ. План передвижения Мышкина по

3 Чтобы более визуально передать суть данной сферичности можно бы сформировать из любой книги, что-то вроде цилиндра, путем соединения ее крайних страниц друг с другом.

${ }^{4}$ Несколько модифицированный термин Х. Халациньской-Вертеляк: посвященный читатель. См.: Н. Chałacińska-Wiertelak, Культурный код в литературном произведении, Poznań 2002.

5 Ф.М. Достоевский, Идиот, Санкт-Петербург 2008, с. 621. В дальнейшем все цитаты даются по этому источнику - с указанием в скобках номера страницы. 
городу определяется пунктами, имеющими возможную связь с упомянутыми героями. Как замечаем, любое усилие проникновения в сферу потенциального присутствия разыскиваемых лиц кончается отступлением от дверей, назначающих будто физическую территорию психической непроходимости. Тем самым, архитектурная, хотелось бы сказать, пл о тность Петербурга кажется вытеснять Мышкина с поля своей имманентной активности, вгоняя его в состояние отрицательно (имплозивно) динамизированного с каждым следующим провалом невольного паралича.

Итак, „заключенный” в области вакуумной внешности князь форсирует будто объектную автономность непроницаемой структуры „города камня”. Мышкин усиленно пытается обнаружить какие-нибудь следы, делающие возможным проникновение в сферу таинственного. Стоя на противоположном тротуаре перед домом Рогожина, князю мерещится его лицо, якобы появившееся на одно мгновение в окне. Хотя он разумно считает данное подозрение невозможным, мысль о мелькнувшем взгляде не покидывает его. После очередного прибытия под дом Рогожина князь копирует будто спекулятивный жест контрольного взгляда в окно, р а ц и о н а л ь н о удостоверяясь в абсурдности своего предчувствия.

Как замечаем, элемент рационального кажется превышать будто раздающийся в подсознании голос интуитивного, отодвигая, тем самым, на задний план любую проблескивающую мысль о возможности осуществления обратной ситуации. Однако, внутренний импульс, четырежды продвигающий Мышкина в сторону рогожинского дома, неспешно всплывает наружу.

Странное ощущение овладело им [Мышкиным] в этом тусклом и душном коридоре, ощущение, мучительно стремившееся осуществиться в какую-то мысль; но он все не мог догадаться, в чем состояла эта новая напрашивающаяся мысль. Он вышел наконец с а м н е с в ой (разрядка моя - Э. Щ.) из трактира; голова его кружилась; но - куда, однако же, ехать? Он бросился опять к Рогожину (с. 624).

Интересно, что исходная плотность психофизической диспозиции князя якобы расслаивается. Машинальное движение телесного слагаемого, управляемого голосом первичного импульса, лишенного доли рефлексии, отделяется от уровня мыслей, остающихся будто в пространстве продолжающегося конфликта рационального с иррациональным.

Таким образом, как можно полагать, сенсомоторное сознание, инстинктивно связанное с объектом вытесняемой мысли, начинает продвигаться инверсно по линии назначенной траекторией хода Мышкина. 
Во время повторного визита у немки князь обыскивает комнату Настасьи Филипповны. Найденную „развернутую книгу из библиотеки для чтения, французский роман Madame Bovary" (c. 624), загнувши, загадочно прячет в карман. Увидев ломберный столик, исписанный мелом, спрашивает, кто играл и где карты. Как наблюдаем, предметное пространство находимых вещей, кажется излучать нить воспоминания прежнего соприкосновения с интенцией мышкинских поисков, которую силится „уловить” князь.

Следуя обратному пути, Мышкин возвращается в гостиницу на Литейной. Примечательно, что место временного проживания сохраняет память о бывшем визите. Эхо этого происшествия стимулирует мысль князя, окончательно позволяя ей полностью прозвучать.

Если Рогожин в Петербурге, то хотя бы он и скрывался на время, а все-таки непременно кончит тем, что придет к нему, к князю, с добрым или дурным намерением, пожалуй, хоть как тогда. По крайней мере, если бы Рогожину почему-нибудь понадобилось прийти, то ему некуда больше идти, как сюда, опять в этот же коридор. Адреса он не знает; стало быть, очень может подумать, что князь в прежнем трактире остановился; по крайней мере попробует здесь поискать... (c. 625-626).

Сознательное усвоение подавляемой мысли есть и движение к ей содержимому, назначающее пространство для его смыслового воплощения. Одновременно, ее артикуляция является неким призывом, будто онтологически детерминирующим установление связи между отправителем и подразумеваемым получателем.

Итак, своеобразная синхронизация психических и физических слагаемых человеческого опыта позволяет Мышкину приблизиться к цели своих поисков. Таким образом, князь призывает разыскиваемое лицо жестом полного осмысления его не пременного присутствия, будто детерминирующего исполнение аналогичного жеста со стороны другого.

Конечно [...] следовало бы ждать Рогожина дома, в номере; но он как будто не мог вынести своей новой мысли, вскочил, взял шляпу и побежал. [...] Он спустился под ворота, вышел на тротуар, подивился густой толпе народа, высыпавшего с закатом солнца на улицу [...], и пошел по направлению к Гороховой (с. 626).

Интересно, что выход навстречу Рогожину сочетается с моментом будто „всплытия" толпы людей на улицу, если так можно выразиться, якобы „рельефирующих" своей телесной плотностью до сих пор плоскую, а вернее, вакуумную для князя поверхность города. Следовательно, как можно полагать, пространство Петербурга приобретает качество дополнительного измерения, выдвигающего, казалось бы, недоступную раньше для постижения реальность в область психофизической активности князя. „Толпа народа” обсту- 
пающая Мышкина со всех сторон, создает сферу межличностного общения, детерминирующего способность к прямой будто чувственной конфронтации сталкивающихся лиц.

Такая ситуация служит емким эфирным пространством для Рогожина, якобы возведенного в поле сенсорной рецепции князя:

В пяти десяти шагах от трактира, на первом перекрестке, в толпе, кто-то вдруг тронул его за локоть и вполголоса проговорил над самым ухом: - Лев Николаевич, ступай, брат, за мной, надоть (с. 626).

Уловление руки князя есть и инициальный жест введения в измерение радиации интер-субъективной реальности.

Озаренный счастьем при виде Рогожина князь ступает вслед за ним. Интересно, что беспокоившие Мышкина до недавнего времени мысли будто „улетучиваются", открываясь на новую познавательную сферу взаимодействия, обусловленную элементом межиндивидного отношения. Князь охотно вступает в диалог с долго разыскиваемым другом, радуясь (не)ожиданной встречи с ним; ведь он же „ждал его сейчас в коридоре, в трактире” (с. 626). Однако эйфорическое состояние Мышкина поддается некому диссоциативному распаду в силу энигматического, лаконического ответа со стороны его собеседника: „Я там был [...] пойдем” (с. 626). На следующий вопрос князя Рогожин отвечает подобным образом. „- А давеча это ты в окно на меня из-за гардины смотрел? - Я..." (с. 627). Как наблюдаем, данное признание отражается широким эхом в сознании Мышкина, воспринимающего ответ Рогожина то ли с удивлением, то ли со странным убеждением в неслучайности такого события. В свете сказанного, закономерным кажется быть наблюдение Х. Халациньской, что все пункты пройденной Мышкиным дороги заранее предусмотрел Рогожин ${ }^{6}$, становясь тем самым немым, мнимо пассивным, наблюдателем развивающегося расследования, которого он являлся предметом.

Обнаруженная целенаправленность друг на друга как в случае Мышкина, так и Рогожина в ходе разведывательного акта позволяет определить данную ориентацию как кругообразную, последовательно поддающуюся некой конденсации, модель взаимозависимости упомянутых лиц.

Интересной в этом контексте представляется просьба идти по двум сторонам улицы, с которой Рогожин обращается к Мышкину. Принятие бинарной позиции главными героями романа Идиот производит впечатление их выразительного разъединения, антаго-

${ }^{6}$ H. Chałacińska-Wiertelak, Idea teatru w powieściach Dostojewskiego, Poznań 1988, c. 19. 
нистического противопоставления7. Однако, интенция, заложенная в основу данной просьбы, приводит как Мышкина, так и Рогожина к одному пункту - дому Рогожина. Как наблюдаем, конфигурация взаимоотношения Мышкин-Рогожин формирует будто веретенообразную модель их контакта - сужаемого (завязанного) в момент их встречи невдалеке от трактира, расширенного в середине во время прохода по противоположным тротуарам, и снова сужаемого у цели их дороги. Интересно, что вырисовывающаяся мобильная картина восстановления единства напоминает покроем процесс алхимического опуса. Как пишет Юнг, „, алхимики стремились к полному единению противоположностей"

это означает, что после достижения ментальной интеграции должна быть дополнительная „дистилляция”, алхимические процессы приводящие к союзу ума и тела, т.е. природы. Но ментальное очищение должно быть первым шагом [...]. Чтобы получить впоследствии соединение, ум (ментальное) должен быть отделен от тела... т.к. соединиться могут только разобщенные вещи ${ }^{9}$

Тем самым, переходное якобы физическое расслоение в отношении Мышкина и Рогожина, выявляющееся в их противоположном стремлении к одной цели, как можно полагать, отнюдь не означает окончательного отделения, а вернее, является оно симптомом промежуточной телесной сепарации, имеющей цель позднейшей интеграции.

Итак, восстановление мнимо прорванной связи совершается вместе с их приближением к дому Рогожина.

Князь подошел к дому с противоположного тротуара; Рогожин же с своего тротуара ступил на крыльцо и махал ему рукой. Князь перешел к нему на крыльцо [...]. - Мы войдем и не услышит никто. - В руках его уже был ключ. [...] тихо отпер дверь в свои комнаты, впустил князя, осторожно прошел за ним, запер дверь за собой и положил ключ в карман (с. 627-628).

Интересно обратить внимание на предмет, представляющий собой будто оперативный центр исполняемого Рогожиным комплекса жестов, а именно ключ.

7 Интересно, что похожую форму взаимоотношения пробретает конфронтация этих героев в пятом разделе второй части романа, см.: Е. Szymkowiak, Этическая цеенность Встречи в системе обшения героев как путь к выявлению истинной натуры человека (на основании романа "Идиот" Ф.М. Достоевского), [в:] Kultury wschodniostowiańskie - oblicza i dialog. Polska - Rosja - Ukraina, red. W. Popiel-Machnicki, t. II, Poznań 2012, c. 156-158.

${ }^{8}$ К.Г. Юнг, Mysterium Coniunctionis, http://jungland.ru/node/2319 (01.12.2012).

${ }_{9}$ С. Розен, Наливая старое вино..., В новую бутылку. Современная алхимическая интерпретация древнего герметического сосуда, [в:] The Interactive Field in Analysis, red. M. Stein, vol. 1 , Wilmette: Chiron Publications, 1955, перевод с англ. Л. Хегай, 2007, http://www.maap.ru/ library/book/140/ (03.12.2012). 
Основная идея данного предмета сводится к общепризнанной директиве, реализующейся процессом замыкания, запирания, закрывания заключения, одновременно имплицируя действие прямо противоположное указанному, т.е. открывание, отпирание ${ }^{10}$. Примечательно, что уже на этом якобы функционально-атрибутивном уровне можно заметить яркую двухполюсность исследуемого предмета. Сведение к одному знаменателю (ключу) двух противоположных качеств, свидетельствует о некой напряженности в пределах актов замыкания и открывания, понимаемых как полярные. Однако, сложившуюся антиномию, как полагается, можно упразднить будто необходимым слагаемым, предоставляющим возможность реализации данных актов, а именно... замочной скважиной. Этот, казалось бы, маргинализированный невзрачный элемент дополняющий целостность указанных процессов будто „пломбирует" место межпозиционного перехода из одной реальности в другую. Интересно обратиться к символике скважины описанной Х.Э. Керлот:

Как символ неба скважина обозначает также конкретный переход из существования в пространстве в существование внепростанственное, из жизни во времени в жизнь вне времени и соответствует зениту ${ }^{11}$.

Итак, способность замочной скважины упразднить антиномию открытия-закрытя можно усматривать в своеобразном объединении данных актов, ведь запертую дверь после извлечения ключа все-таки можно считать зрительно открытой благодаря щелевому отверстию в виде замочной скважины.

Таким образом, Рогожин, извлекая ключ их замочной скважины, как можно полагать, протягивает будто силовой луч земной действительности в поле сверхъестественной реальности. Тем самым, наружное закрытие, или вернее, отделение двух миров ослабляется, делая возможным подразумеваемое проникновение позднейшего, неким образом, о ж и д а е м о г о петербургского элемента...

В свою очередь, интересно сослаться на этимологическое происхождение слова карман. Как пишет М. Фасмер, некоторые ученые (напр. Брюкнер) сближают это слово с греческим „корßаvás”, обозначающим „храмовую сокровищницу”, а также с турецким словом „karman”, обозначающим „врываться", „проникать”12. Примечательно, что храмовая сокровищница имеет свою библейскую мотивацию, появляясь в Евангелии от Иоанна.

${ }^{10}$ W. Kopaliński, Stownik symboli, Warszawa 1990, c. 145.

${ }^{11}$ J.E. Cirlot, Stownik symboli, указ. соч., с. 297.

12 М.Фасмер, Этимологический словарь русского языка, http://vasmer.narod.ru/p260.htm (27.11.2012). 
В этом месте Иисус Христос обращается к фарисеям со своим посланием:

Я свет миру; кто последует за Мною, тот не будет ходить во тьме, но будет иметь свет жизни (8 Иоанн, 12).

К нему была и приведена грешная женщина.

Тут книжники и фарисеи привели к Нему женщину, взятую в прелюбодеянии, и, поставив ее посреди, сказали Ему: Учитель! эта женщина взята в прелюбодеянии; а Моисей в законе заповедал нам побивать таких камнями: Ты что скажешь? (8 Иоанн, 3-5).

Замечаем, что обращение к Иисусу с подразумеваемой просьбой о разрешении наказать грешницу, ставит женщину в греховном положении не учитывающем, согласно Божьим заповедям, данным Моисею, возможности принять новозаветное таинство прощения и отпущения грехов. Уверенные в знание Священного Писания фарисеи требуют телесного наказания женщины. Однако, на слова Иисуса:

кто из вас без греха, первый брось на нее камень" (8 Иоанн, 7)

фарисеи отступают.

Женщина! где твои обвинители? никто не осудил тебя? Она отвечала: никто, Господи. Иисус сказал ей: и Я не осуждаю тебя; иди и впредь не греши (8 Иоанн, 11).

Правда, Иисус Христос не дает таинства исповеди, так как в то время оно не было еще установлено, однако, можно в ответе Иисуса обнаружить его некое предзнаменование, предвещающее непременность последующих действий...

Следует обратить внимание на другой, в свете наших высказываний весьма существенный, вопрос. Как наблюдаем, Иисус в своей речи к фарисеям наглядно показывает, что каждый человек грешен, поскольку никто не может с чистой совестью сделать жест, наказывающий женщину. „Вы судите по плоти; я не сужу никого” (8 Иоанн, 15). Интересно, что Иисус делает упор на плоть - тело, а тем самым, на внешнюю часть человеческой сущности. Такое осмысление ограничено перцепцией лишь наружности, не принимается во внимание внутренний ведь Божий образ в природе человека. Осуждение по плоти есть и „заключение” человека в пространстве вещей, предметов, наконец, объектов, оцениваемых лишь по их поверхностному, а затем несовершенному, ибо „бракованному” (недовоплощенному) облику. Иисус не осуждает а, как раз наоборот, 
implicite „подает руку” женщине, выявляя, тем самым, свою по истине человеческо-Божью природу.

Представленную библейскую референцию, как следует, можно применить к анализированной нами сцене. Извлеченный из двери и положенный в карман ключ, кажется охватывать собой (содержать в себе) пространство запертой ним квартиры, назначенной пятном греха - убийством Настасьи Филипповны. Перенос его содерж им ого в область храмовой, „намазанной” присутствием Иисуса, действительности можно считать реминисценцией представленной библейской сцены.

Итак, как можно полагать, князь, узнав об убийстве Настасьи Филипповны, подобно Иисусу Христу, не осуждает преступления своего друга.

Наконец он прилег на подушку, как бы совсем в бессилии и в отчаянии, и прижался своим лицом к бледному и неподвижному лицу Рогожина; слезы текли из его глаз на щеки Рогожина (с. 634).

Жест Мышкина есть и бессловесное обращение к Рогожину - „Я не осуждаю", упраздняющее осудительное, ибо объектное отношение к другому, зато знаменующее открытие на полное измерение тождественной ему человеческой природы.

Следует опять привести строку из Евангелия от Иоанна.

Сии слова говорил Иисус у сокровищницы, когда учил в храме; и никто не взял Его, потому что еще не пришел час Его (8 Иоанн, 20).

Значимое отсутствие слова прощающего и, следовательно, отпускающего грехи можно считать потенциальной, хотя пока еще неоформленной возможностью исповеди, осуществимой в ожидаемом будущем. Инициальным жестом этого акта есть и смысловое бессловесное объятие Рогожина Мышкиным. В свою очередь, последовательным ответом - удовлетворением за вину ближнему можно считать... первые слова обращения Рогожина к Мышкину в поезде Петербургско-Варшавской железной дороги.

Черноволосый сосед в крытом тулупе все это разглядел, частью от нечего делать, и наконец спросил с тою неделикатною усмешкой, к которой так бесцеремонно и небрежно выражается иногда людское удовольствие при неудачах б ли ж н е г о: (разрядка моя - Э. Ш.) - Зябко? (с. 6).

Изреченное слово, как можно полагать, о б н и м а е с своим человеческим сочувствием целое мышкинской личности, дополняя, тем самым, ценность аналогичного - ответного акта со стороны другого.

Как замечаем, ожидаемая реакция переносит нас в будущее, а вернее, к началу произведения. Такое наблюдение позволяет вы- 
двинуть мысль о некой кругообразности, цикличности в построении романа ${ }^{13}$, выявляющихся как на уровне главной фабульной линии текста, так и на уровне меньшего фрагмента (очерченная нами линия хода Мышкина по городу), функционирующего будто в качестве pars pro toto произведения. Данный анализ можно считать лишь предварительным эскизом, требующим глубинной эксплорации текста в целом.

13 Другим аргументом за предложенную цикличность, требующим тщательного анализа можно бы считать мотив Швейцарии, отсутствующий в непосредственном фабульном пространстве, зато будто (вне)временно сцепляющий крайние сцены романа. 